\title{
Sustainable development in Canadian forestry in the face of changing paradigms
}

\author{
by J.P. (Hamish) Kimmins
}

The present world population is reported to be about 5.7 billion people and this figure is projected to reach about double this number (i.e. 11 billion) in the time it takes to grow a tree crop in many Canadian forests - about $100 \pm 20$ yr. Predictions of as many as 16 billion or even 25 billion were reported from the recent U.N. conference on world population in Cairo as the ultimate population level. All these predictions are speculative, but clearly population growth, whatever level it eventually reaches, constitutes the major long term threat to the world's forests.

With an annual increase in population of about 100 million, and an annual per capita consumption of about $0.7 \mathrm{~m}^{3}$ (Sutton 1993), the current annual increase in global wood demand is estimated to be 70 million $\mathrm{m}^{3}$. This is similar to the $1993 \mathrm{annu}-$ al allowable cut of British Columbia of 72 million $\mathrm{m}^{3}$. If this estimate is correct, the world will have to locate a source of wood products equivalent to another BC every year if the demand is to be satisfied in a sustainable manner. This seems unlikely, both because there is not enough unmanaged, uncommitted forest in the world to sustain such an expansion of cutting for more than a decade or two, and because most of the remaining unmanaged forest is in countries that are presently poorly equipped to manage their forests sustainably.

In spite of moves to reuse and recycle wood products and reduce wood waste, it seems likely that per capita consumption of wood will increase as the environmental benefits of using wood products are more widely recognized. The energy benefits of well insulated wood frame houses, and the much lower energy costs of wood in comparison with steel, brick and concrete, should result in greater use of wood as governments introduce policies to limit the use of fossil fuels. Product substitution will probably occur if scarcity of wood raises the price sufficiently, but environmental considerations will generally make wood the product of choice. Alternatives to wood fibre for paper and packing are proposed by those who wish to reduce forest harvesting, but since much of this material is made from the waste from solid wood products manufacturing, it is difficult to see how this substitution would achieve their goal. In many parts of the world, forests would have to be cleared to grow alternative fibre crops.

As stewards of $10 \%$ of the world's forests, $14 \%$ of the global softwood inventory, $50 \%$ of the global export market of softwood lumber and $56 \%$ of newsprint exports, Canada has a major responsibility to contribute its share of the world supply of wood products. Failure to do so would transfer more of the task of providing wood products to other countries, many of which have less well regulated forestry, and forest ecosystems that are less able to sustain the accelerated timber harvest.

The present international acceptance of the concept of certification ("green labeling") of wood products holds great

\footnotetext{
${ }^{1}$ Faculty of Forestry, University of British Columbia, Vancouver, British Columbia, Canada V6T 1 Z4.

A paper presented at the Timber Supply in Canada Conference, Kananaskis, Alberta, 15-18 November, 1994.
}

promise as a market mechanism to move from unregulated exploitation, or forest management that is non-sustainable, to well regulated and sustainable forestry. Certification will, hopefully, head off any "green gold rush" to fill the expanding world demand by non-sustainable forest exploitation, and will certainly sustain, and could even increase Canada's share in the international market. However, until certification is in place, it is important that Canada maintain its market contribution. Because of the importance of timber in the Canadian economy, forestry also has national, provincial and local responsibilities to provide jobs and raw materials, and to create the wealth needed to fuel our economy.

Clearly, there is a need to sustain, and, where environmentally acceptable, to increase the supply of timber from Canada's forests. However, the public now views its forests as much more than a supply of wood products and provider of wealth and employment, there has been a "paradigm shift". Many other forest values must be sustained, and this poses a major challenge to the future supply of Canadian lumber. In this paper I will review the history of changing paradigms in Canadian forestry and some dimensions of the currently emerging paradigm. I will conclude with a discussion of the implications for this new paradigm for the future timber supply, and will present my vision of the future of forestry and timber supply in Canada.

\section{Changing Paradigms in Forestry}

The earliest stage in the relationship of humans to forests typically involves exploitation: the use, harvest or removal of forests with no thought for their renewal. When human numbers are low and their technology weak, nature can more than replace what is taken. Exploitation does not threaten forests at this stage. However, as human numbers and technology increase, and as forests become thought of as threatening to human welfare or as an impediment to other land uses (e.g., agriculture), deforestation and local or regional shortages of various forest resource values develop. The exploitation paradigm is not concerned with sustaining forests and their values, and generally considers the supply of these resources inexhaustible.

The response of governments to the loss of, or threats to, forest values caused by exploitation has historically been the genesis of forestry. Although the origins of forestry have always been rooted in the desire to sustain forests or the supply of one or more forest values, the initial stage of forestry has frequently failed to achieve its goals. This has usually been because this stage is generally based on a paradigm of central control and a set of laws and regulations that collectively ignore the ecological characteristics of forested landscapes, and the variability in these characteristics both spatially and over time. The "administrative" paradigm of this early stage in forestry may succeed in sustaining some forest values, but many others are degraded, and in some cases none of the forest values are maintained at desired levels.

As the shortcomings of "administrative forestry" are recognized and become unacceptable to an evolving society, forestry switches to a new paradigm: ecologically-based forestry. In this 
stage, the laws, regulations, and management objectives of the administrative stage are modified to reflect ecological constraints on how the forest can be managed if certain values are to be sustained. Based on an ecological site classification (e.g. the biogeoclimatic classification system of $\mathrm{BC}$ ), site-specific regulations, practices and silvicultural systems are developed that are consistent with sustaining ecosystem function, log supply, employment and wealth creation, the habitat of a variety of wildlife species (mostly "game" species), and watershed function and fish habitat. Centralized control of forestry is replaced by local, on-the-ground decision-making to ensure that site-specific management which respects local ecological conditions is applied.

The ecological (ie. scientific) paradigm for forestry is generally successful in sustaining a variety of desired values. However, it has generally not satisfied all of the values of a wealthy, "post-industrial", society. Ecologically-based forestry does not necessarily maintain the aesthetics of stands and landscape throughout the rotation, and does not necessarily achieve what society thinks it means by "biodiversity". Nor does this type of forestry conserve and sustain the "spiritual" values of mature or "oldgrowth" forests. As a result, there are social pressures to develop yet another paradigm for forestry: "social forestry". The essence of this third paradigm is forestry that "respects nature", "sustains biodiversity", maintains "late seral or old growth" forest conditions, minimizes ecosystem disturbance, and maintains the aesthetic and spiritual values of stands and landscapes essentially unchanged.

Canada is a young country with a relatively short history. Forest exploitation on a significant scale goes back less that 300 years, and it continued in some parts of the country until the early part of this century. "Administrative forestry" was slowly introduced over the first half of the century in response to actual, or the perceived threat of, forest depletion. As we approached the fourth quarter of the century, evidence of the shortcomings of this paradigm were accumulating and the environmental awareness of the public was increasing. Led by foresters, researchers and academics, this resulted in a slow but steady change to the ecologically-based paradigm, a change that accelerated as the general public gave voice to their environmental concerns. Across the country, forestry is progressing from the "administrative" to the "ecological" paradigm.

However, as this change occurred, the environmental wave of the 1980's and early 1990's swept over forestry, with demands that forestry move directly and rapidly to the "social" stage of forestry. Concern over wilderness, inadequate forest regeneration, ugly clearcuts, stream and soil damage, and perceptions that forestry damages biodiversity have stimulated demands for a "kinder, gentler forestry" that is "respectful" and creates little or no disturbance to the ecosystem. "Ecosystem structure", "ecosystem health" and "ecosystem integrity" have become the buzzwords, and for a while traditional concerns about sustaining forest productivity and the concomitant social values were replaced by concerns about "rare and endangered" species, snags, "coarse wood debris", "connectivity" of the landscape, "fragmentation" and biodiversity.

Many of the issues in the emerging paradigm have been borrowed from different latitudes, different forest types, from ecological theory developed for specific rather than general situations, and from experience gained in particular ecological zones. The emerging paradigm offers the potential to provide a greatly improved framework for sustainable management of many different forest values, but it also challenges, and indeed threatens, several traditional social values provided by forests, including timber yields.

\section{Dimensions of the Emerging Paradigm}

The precise dimensions of the emerging paradigm are not yet clear. However, the following is a partial list of concepts that have been advanced as candidates, and some are reflected in new legislation (e.g., the 1994 Forest Practices Code of BC):

\section{a. Forests Must be Managed in a Way that Sustains Ecosystem Integrity ${ }^{2}$}

This is an essential component of any system of sustainable forestry. The difficulty is, what does it mean? I offer the following definition:

\section{A forest ecosystem has integrity if:}

- its structure and species composition, the rate of its ecological processes, and its ability to resist change in the face of disturbance or stress are within the characteristic range exhibited historically by that ecosystem.

The historic reference period is that period during which regional climate has not changed enough to cause a significant directional change in ecosystem potential or processes of change.

- it is developing by autogenic successional processes towards a later successional condition at rates and by pathways that are characteristic of that ecosystem, or is already at a late seral stage.

This definition of ecosystem integrity views ecosystems as continually changing. "Integrity" cannot be defined by "snapshot" evaluations, nor can it be based on steadystate or equilibrium concepts.

One frequently hears the assertion that "clearcutting destroys the integrity of forest ecosystems, and of old growth forests", and the corollary that "a forest that regrows after clearcutting is not a forest ecosystem", because the integrity of the ecosystem has been destroyed.

If forest harvesting is conducted in a way that impairs the processes of ecosystem recovery from disturbance, the integrity of that ecosystem has indeed been compromised. However, if the harvesting converts the ecosystem condition from one seral stage or condition to another without impairing the processes of recovery, then its integrity as an ecosystem has not been damaged.

Much of the debate over ecosystem integrity results from the confusion between ecosystem integrity and the integrity of a particular seral stage.

Clearcutting destroys the integrity of the old growth condition or the climax/late seral stage of west coast old growth forests. However, unless poor road location, construction, maintenance, and/or de-building cause slope instability and soil erosion, or where loss of root strength causes slope instability, or where insufficient soil disturbance permits ericaceous or other shrubs to dominate the site after logging, the prompt regeneration that normally occurs in these west coast forests ensures a rapid return to forest conditions. The following definition of the integrity of a seral stage is offered:

\footnotetext{
${ }^{2}$ For a discussion of ecosystem integrity, see Woodley et al. (1993).
} 
A particular seral stage of a particular ecosystem has integrity if:

- its structure, species composition, ecological condition and process rates are within the characteristic range exhibited historically by that seral stage of that particular type of ecosystem.

The historical reference period is the same as for Ecosystem Integrity.

The integrity of a particular seral stage of a particular forest ecosystem type is lost as the processes of succession, or disturbance-driven retrogression, lead to the replacement of that stage by another.

This change in successional conditions does not threaten the integrity of the ecosystem if the condition of the new seral stage satisfies the criteria of Ecosystem and Seral Stage Integrity.

If the objective of management is to maintain the conditions of a particular seral stage, then management must be limited to those practices that maintain the ecosystem within the historical range observed for that seral stage. If, on the other hand, the objectives are to move the ecosystem to, and then maintain it in, a different seral stage, or to allow it to pass through a series of stages between successive harvest-related disturbances, a different set of management regimes would be consistent with maintaining ecosystem integrity.

Ecosystems are dynamic. There is continual change. In some ecosystems this is mainly on a tree-by-tree basis forming small canopy gaps. In other ecosystems it is mainly by large scale, stand-replacement disturbance. The former tends to maintain the integrity of both the seral stage and the ecosystem. The latter generally maintains ecosystem integrity, but general destroys seral stage integrity.

A significant area of British Columbia (e.g., the wetter subzones of the Coastal Western Hemlock zone, many areas of the Boreal Zone, humid areas in the Engelmann SpruceSubalpine Fir zone, and parts of the Interior Cedar Hemlock zone) has closed forest communities only because of periodic large-scale stand replacing disturbances such as fire (mainly) and wind (less common). By reducing shrub and herb competition, providing good seedbed conditions for trees, and improving soil physical and chemical conditions for tree growth, disturbance promotes abundant tree regeneration. In the long term absence (several centuries or even millennia) of significant natural stand-replacing disturbance, unmanaged forests in these areas slowly lose forest cover until their structure is open woodland, muskeg, or shrub heath rather than closed forest. Where this is true, the integrity of the forest ecosystem may require periodic disturbance, rather than that disturbance being a threat to its integrity.

\section{b. Forests Must be Managed to Sustain Ecosystem Health $^{3}$}

The traditional view of a healthy forest is one in which:

- trees are vigorous and productive

- there is rapid biomass accumulation and nutrient cycling

- insects and diseases have little negative effect on the development of tree populations and plant communities

${ }^{3}$ For a discussion of forest ecosystem health, see Kolb et al. (1994).
- processes of ecological succession and stand development are proceeding at rates that are characteristic of the particular ecosystem

- the ecosystem has high "vitality" and is able to withstand stress.

In contrast, the interpretation of forest health made by many in the "environmental movement" (i.e. a "green" definition) is that a healthy forest is one in which:

- the forest has reached it's peak of development: a late seral stage

- the canopy is multi-layered with many large gaps and the trees are uneven-aged

- there are many large, dead, deformed, broken and partlydecayed trees and decaying logs that provide habitat for the animals that use these "structures"

- rare and "specialist" species which are considered to be indicators of a healthy forest ecosystem are present.

This diversity of interpretations can be found throughout the debate on forest health. It is even reflected in the new BC Forest Practices Code, leaving it unclear as to how a forester should approach the issue of managing for forest health!

My interpretation of forest ecosystem health is that a forest is healthy if the structure, species composition and ecosystem processes are all within the historical range exhibited by the seral stage that the forest is in, or the stage that it is being managed for. If one is managing a forest to sustain old growth condition, then many dead, diseased, broken and damaged trees, lots of canopy gaps, incomplete stocking, and lots of decaying logs may constitute a healthy ecosystem condition in some types of forest. In contrast, if one is managing that same area as a productive, even-aged second growth forest, the presence of these very same features would indicate a forest in poor health. However, if one was managing this second growth forest to maintain some late-seral (i.e. old growth) wildlife habitat values, the presence of a few snags, misshapen and diseased trees might be entirely consistent with the objectives of management and the stand condition might be considered healthy, even though such a combination of ecological conditions and structures might be uncommon in unmanaged forests.

As is the case with the definition of human health and quality of life, there is no single yardstick. At each stage of human life, there are norms of health. One would not expect babies and teenagers to have the same health problems and physical expectations, nor would young and old people expect to be in the same physiological condition. Each seral stage of a particular forest ecosystem type is characterized by different "health" conditions. In many forest types, forest pathogens play an important role in stand thinning and the creation of habitat for wildlife, and a certain level of disease-related mortality in a forest is consistent with a "healthy" forest. However, epidemics of insects or diseases, and species composition, stand structure and stand density that are outside of the "normal" condition for a particular seral stage would be considered "unhealthy". Previously fire dominated forests on the rain shadow side of the Cascade mountains in Oregon and Washington that have been protected from fire for many decades have developed stand structure, density and species composition characteristics that render them highly susceptible to fire and insects, and which 
cause "unnatural" levels of competition for moisture. These forests would have to be considered unhealthy. They are not in a "natural" condition. Similarly, managing forests that are naturally even-aged, and in which diseases have been controlled naturally by large-scale, stand replacing disturbances, as uneven-aged forests by partial harvesting can create uncommon conditions and an imbalance in the historic disease-host relationship: the result - an incidence of disease much higher than that of most unmanaged forests. Examples of this can be found in the mistletoe-lodgepole pine and mistletoe-western hemlock relationships in BC.

\section{c. Forests Should be Managed to Maintain Late Seral or Mature Forest Conditions}

Historically, many of the world's forests have been managed to maintain early- or mid-seral conditions because these stages often provide the highest productivity of desired timber products. Managed sustainably, these forests have integrity both as ecosystems and as early- or mid-seral forests, and would satisfy the traditional definition of a healthy forest. In contrast there is an adulation of late seral, climax, or old-growth forests in the forestry paradigm that is developing in the public debate on forestry.

In forest landscapes in which large scale disturbance is either infrequent or where it advances rather than retards succession, management for late seral species is consistent with the historical ecosystem condition. Large scale disturbance from harvesting in such forests may sustain ecosystem integrity but cause the ecosystem to change to an earlier seral condition over much of the landscape, a condition that may occur naturally but infrequently.

In disturbance-driven or disturbance-dependent landscapes, management for late-seral species will often result in widespread ecosystem conditions that are rare in unmanaged forests, leading to reduced forest health and the possible reduction or even loss of the integrity of the forest ecosystem (e.g., the problems of loss of forest cover, or the increase in pathogens, in the absence of periodic large scale disturbance discussed above).

It therefore seems as inappropriate to pursue late seral conditions for all forests as it does to put all forests into early- or mid-seral conditions. Early- or mid-seral forests are appropriate for short-to-medium frequency disturbance forests. Mid- to lateseral forests are appropriate for medium frequency or lower intensity but frequent disturbance regimes. Late-seral forests are an appropriate goal for naturally low frequency or very low intensity/scale disturbance events. These conclusions are only valid, however, if one's objective is to maintain historical ranges of species composition, productivity, biodiversity, wildlife habitat and other ecosystem and landscape variables.

Many in the public debate seem to devalue young forests. We do not devalue babies, children or teenagers in human society, so why should we devalue young forests, which, like children, grow to become older, more mature forests in time? In many Canadian forests, flowering shrubs and herbs and broadleaved hardwood tree species only grow in young, disturbancedriven forests. In the Forest Practices Code of $\mathrm{BC}$ there is a recommendation to maintain late-seral forest conditions, yet the code also promotes a hardwood component for our forests. These two ideas are inconsistent with the known ecology of the species in these two different seral stages. In human society, we put value on all stages of human life and aspire to have all age classes represented in our population. Why then, would we not achieve a range of forest ages on the landscapes as long as the landscape pattern of age classes was consistent with our management objectives. Young rain forest is as natural an ecological condition as old rain forest, yet many people only seem to value old growth rain forest. Forest harvesting, whether by clearcutting or partial harvesting, will inevitably alter the age class structure of some forets compared with the unmanaged condition, but as long as there is an acceptable balance of age classes across the range that occurs naturally and an acceptable landscape pattern of age classes, it is difficult to understand the frequent public rejection of young forests.

\section{d. Coniferous Forests Should be Managed to Maintain a Deciduous Hardwood Component}

For aesthetic, recreational and biodiversity reasons, the emerging paradigm advocates mixtures of conifers and deciduous hardwoods. Equally important, though not always mentioned, is the role of deciduous hardwoods maintaining soil fertility, including the role of some species in nitrogen fixation.

Until quite recently, foresters in many temperate coniferous and boreal forests worked diligently to reduce the hardwood component in coniferous or mixed-wood forests. The hardwoods lacked commercial value, and under the "administrative forestry" paradigm they were to be controlled and replaced by commercially valuable softwoods. As the economic value of deciduous hardwoods has increased, and as our understanding of their important contributions to long term site productivity, wildlife habitat and economic production has increased, hardwoods have gained respectability, and in some regions are beginning to receive preferential treatment.

Many of the deciduous hardwoods in Canada are disturbancerequiring: e.g., birch, aspen, cherry, alder. Consequently, the promotion of hardwoods is inconsistent with the objective of maintaining late-seral forest conditions as noted earlier.

\section{e. Uneven-aged and Old-growth Conditions Should be Retained by "Soft-footprint" (i.e. Low Disturbance), Long-rotation, Partial Harvesting Systems}

Multiple canopy levels are correlated with high species diversity in many tropical rain forests, and a general relationship has been demonstrated between structural diversity of forest canopies and bird species diversity in some temperate forests. This has led to the belief by some that uneven-aged, multi-storied forests at temperate and northern latitudes will be both more stable and will support higher levels of species diversity than even-aged, even-canopied forests.

Natural unmanaged forests vary from very extensive areas of even-aged monoculture forests through mosaics of even-age monocultures of different ages, even-age mixed species stands, to uneven age, multi-canopy layer monoculture forests, and unevenage, multi-canopy layer mixed species forests. The various indices of biodiversity and stability in these forests range from high to low, and attempts to find simple relationships between canopy structure, species diversity and measures of ecosystem stability that apply to all forests have not been successful. The best strategy would appear to operate within the range of canopy structure, age classes and species diversity that are characteristic of the seral stage being managed for in the ecological site type and zone in question. 
There also appears to be a feeling that old growth or mature forests are better than young forests because forests are constantly striving to obtain this condition through autogenic succession. The implication is that management should attempt to accelerate autogenic succession and, once climax conditions are achieved, to maintain them by emulating gap-phase regeneration strategies through uneven-aged management. This appears to be a valid timber production objective in forests that are part of xerarch or hydrarch succession because net primary production is maximum in the late-seral or climax stages of these ecosystems. But in mesarch succession, both productivity and biodiversity tend to be greatest in mid-seral, periodically disturbed forests. Thus, late-seral conditions may be an appropriate goal for some landscape units, but not others, depending on one's management objectives.

In the debate over old growth, there is often the implicit assumption that one can classify forests very simply as "old growth" or "not old growth". Definitions were advanced as to which forest conditions could qualify as old growth, and we use these to decide which forests could become candidates for possible old growth "protected area" status. It was soon realized that this approach leads to the rejection of many old and magnificent forests as potential reserves because they lack several of the key characteristics. There was also the realization that mature, late-seral stage forests in different ecological zones require different definitions of old growth condition. The "archetypal" definition of old growth developed in the Pacific Northwest U.S. states is not appropriate, without modification, for all forests. This led to the useful concept of an "old growthness index" (OGI). Forests are scored on a list of old growth attributes, and the scores summed to give an index of old-growthness.

If one accepts this approach to old growth definition, it becomes possible to manage forests to have any desired index of old-growthness, according to one's management objectives. Applying some of the concepts of "New Forestry" and "Ecosystems Management" from the U.S. permits the retention of old growth-like structures in managed second growth where this is an objective, giving these second growth stands much higher OGI values than in traditionally managed second growth.

\section{g. Above All, Management Should Protect Biodiversity}

There is widespread concern over species loss in tropical rain forest caused mainly by deforestation accompanying changes in land use from forestry to agriculture, but also in some cases by exploitative logging. This concern has been transferred to concern over logging at boreal and temperate latitudes, often with little consideration of the differences between biodiversity issues in the tropics and at higher latitudes. Nevertheless, there is now almost universal acceptance that biodiversity is an issue in forest management, and that forests should not be managed in a way that causes the disappearance of a species from across its range.

The difficulty with the biodiversity issue is that there are many different measures of biodiversity, and that almost any natural or human caused disturbance will benefit some species and be negative for others. It is simply not enough to say "we must manage for biodiversity". More detail is required. Do we want to increase biodiversity? Many measures of diversity are increased in west coast old growth forests when they are put under timber management, while some are decreased. Concern about biodiversity has generally supported the idea of sustaining or increas- ing it; now some groups are against logging temperate old growth because it would increase some measures of diversity above what we believe to be the historical levels for that "ancient" forest. Clearly, explicit biodiversity goals must be set that go beyond issues of single species like the northern spotted owl.

The various measures of forest diversity include:

stand-level biodiversity (alpha diversity)

- species "richness" (the number of species)

- species evenness (the relative abundance of the different species)

- structural diversity (number of canopy layers, canopy length, frequency and size of canopy gaps, snags, and coarse woody debris: coarse wood debris is featured by some as a key habitat feature, but recent research suggests that in many forests stumps and roots may be as or more important than decaying logs, so the issue is more complex than simply the abundance of the latter). landscape-level biodiversity (beta diversity)

- variation in species richness and evenness, and in stand structure across the landscape. This may reflect ecological diversity across the landscape or the history of landscape disturbance and successional recovery.

\section{temporal biodiversity}

- variation in both alpha and beta measures of biodiversity over time as a result of disturbance and successional recovery. ecosystem diversity

- the variation in the physical and chemical characteristics of the landscape: climate, geology, soil, topography. Ecological diversity is the framework within which biodiversity develops due to the interaction between disturbance and processes of successional recovery.

Forest management should first identify ecosystem diversity. It should then set objectives for desired temporal patterns of biodiversity. Within this space-time framework, specific landscape patterns and stand-level biodiversity objectives should be established. Genetic diversity must also be protected at both stand and landscape levels. Only when this is done should we expect to achieve society's biodiversity goals, and a balance between biodiversity and the other values of the forest.

\section{Future Paradigms: A Vision of the Future for Canada's Forestry}

Alvin Toffler, the American futurist, noted that when the institutions that serve society change more slowly than society's expectations of those institutions, we have "future shock".

Forestry in Canada and many other parts of the world is facing "future shock". Forestry is the art, science and business of managing forests to sustain a balance of values, goods and services desired by the landowner. Therefore, by definition, forestry must change as the "owners" of the public forest (the public), and of the global environment of which all forests are an important part, change their expectations and desires. However, with the recent escalation in the rate of change in these expectations, coupled with the long time scale of forestry and the inertia in both government regulations and forest industry practice with respect to change, forestry has lagged behind changes in public attitude. Future shock in forestry lies behind much of the recent conflict over how forests are managed.

Although forestry has an absolute obligation to change as public attitudes change, there is a parallel responsibility to resist changes that, according to the knowledge and experience of foresters, are inconsistent with the long-term vision that the public has for its forests. For example, old, unmanaged western hem- 
lock forests in the Coastal Western Hemlock (CWH) biogeoclimatic zone of $\mathrm{BC}$ characteristically have significant infections of dwarf mistletoe. In the past, large scale stand-destroying fires in the drier subzones of $\mathrm{CWH}$ have replaced the hemlock with Douglas-fir every few centuries. This has resulted in the development of largely mistletoe-free second growth hemlock beneath a Douglas-fir overstory, and maintained a moderate diversity of tree species in the forest, including seral hardwood species. With fire suppression, the mistletoe gradually spreads through the new forest from surviving infected trees, and the multi-species, relatively even-aged, fire-origin forest is slowly replaced on many sites by uneven-aged, monoculture hemlock forest unless a new stand-replacing disturbance, such as clearcutting, occurs. Partial harvesting of such distrubancedriven forests can lead to reduced tree species diversity and a greatly increased incidence of stem-deforming mistletoe infection. If society wants to bequeath to their great, great, great grandchildren a forest of species composition, structure, diversity, health and productivity similar to that which we inherited from the historical regimes of natural disturbance, we have the obligation to replace the ecological effects of those disturbances that we now prevent by creating appropriate harvesting-caused disturbance effects.

Given this dual responsibility to change, but to resist inappropriate change, I offer the following vision for the future of forestry in Canada.

\section{There must be an ecological classification of the forest.}

There can be no vision for the future of our forests, and no ecologically-based land allocation strategy, until the ecological variability (the ecological diversity) of our forests has been recognized and described. We cannot formulate a rational conservation strategy (e.g., a network of ecological reserves based on a "gap analysis") until we know what it is we are trying to conserve, and where variations in resource values are located across the country. The biogeoclimatic classification system provides an excellent foundation for the classification of diverse forest resource values in BC, and analogous systems exist, are being developed, or should be developed in other provinces. The process of ecosystem inventory and classification must be completed for the whole country.

\section{The land use objectives and the desired future state of the forests must be decided.}

Although it is unreasonable to expect that land use decisions will ever be completely fixed and unchanging, the time has come to make a long-term commitment to how forest lands will be used. The Commission on Resources and Environment (CORE) is presently formulating a land use strategy for $\mathrm{BC}$, dividing forest land between wilderness, parks, "special management" zones, and "working forest". The new BC Forest Practices Code addresses forest practices for the working forest, but fails to articulate what the forest landscape, and particular types of forest within this landscape, should look like at various times in the future. In the absence of this future vision it is unlikely that the Code will achieve the results the public anticipates from it. Without a vision, the code becomes analogous to a technical building code without an architectural plan as to what the completed building project should be like.

\section{The intensity of forest management must be zoned.}

Land use planning must go beyond the level undertaken by the BC CORE process. Within the working forest, decisions must be made about the type of forestry that is to be practiced: intense vs. extensive. Part of the spotted owl/wilderness controversy in the US Pacific Northwest resulted from the differences in forest structure, composition and wildlife values, at both the stand and landscape level, between unmanaged old growth and intensively-managed, high-yield timber plantations on private forest land, and the public's belief that all forests in the former would eventually become like the latter. An alternative to vast old growth reserves, suggested by Jerry Franklin, was "New Forestry". Management of most of the landscape to retain "old growth structures" such as snags, wildlife trees and coarse woody debris, reduces the need for large reserves by ensuring that these "biological legacies" are passed on from rotation to rotation across the whole landscape.

I believe a hybrid between these different approaches is appropriate for Canada. Once the network of ecological, wildlife and park reserves has been created to satisfy the $12 \%$ protected area commitment of the federal government, the remaining commercial forest land should be divided between areas used for intensive management (primarily for wood products), and areas managed extensively. The latter should incorporate landscape patterns and stand structures that mimic those features of natural, unmanaged landscapes that are necessary to achieve specific objectives for wildlife, watershed, and other land values. Timber supply increases from the intensively managed areas would compensate for the reduction in timber supply due to the creation of new protected area reserves, and for the reduced supply from areas managed to retain specific structures and landscape patterns.

The designation of overall land use and the zonation of intensity of management within the commercial forest should be closely related. In a forest industry-based, export-driven economy such as that of $\mathrm{BC}$, it is unlikely that society will dedicate enough of its landscapes to "protected areas" to satisfy all concerns about wildlife, endangered species and biodiversity. Extensive management across much of the landscape is seen by many as ultimately a better conservation strategy than fighting for significant further increases in protected areas (as occurred in Oregon and Washington) with all the social and economic problems that result. Careful analysis of the conservation, social and economic tradeoffs between these two strategies is needed.

\section{Ecosystem management must replace timber man- agement}

The focus of management during the "administrative" stage of forestry has generally been on strategic and industrial supplies of timber, as it was during the pre-forestry exploitation stage. The ecologically-based forestry paradigm has generally included management for a wider range of values, but has usually had a strong silvicultural bias. The paradigm that is developing for the social forestry stage that we are now entering includes a much wider range of values. Clearly, this paradigm is centered on managing forests as ecosystems rather than mainly as timber resources, important though this value is, and, I believe, "always" will be. But what does "ecosystem management" really mean? Is it just another "buzzword" in the ongoing forest-management debate?

Ecosystem management requires that we recognize forests for what they are: ecosystems. Forest ecosystems are ecological systems that exhibit the following attributes: 
structure

plants, animals, microbes, geological substrate (soil), and atmosphere (climatic variables). Trees are the dominant plants.

\section{function}

capture of solar energy as plant biomass and its conversion to animal and microbial biomass to give ecosystems a "trophic" structure; circulation of nutrients to accomplish energy capture, storage and transfers; regulation of hydrological processes.

\section{complexity and inter-connectedness}

ecosystems have many components and processes, many of which are interconnected and interdependent. Events and conditions in ecosystems are multiply-determined; there are few simple causal relationships, which renders prediction of future states of the ecosystem, and response to disturbance, difficult in the absence of detailed knowledge of ecosystem structure and function, or experience, or both.

\section{change over time}

all ecosystems are undergoing continual change as a result of external disturbances and the ecosystem's internal processes of autogenic succession that lead to recovery from disturbance.

Sustained management requires that policies, regulations and practices respect these ecosystem characteristics and how they vary spatially across the local landscape and from one region to another.

Ecosystem management is simply forest management that respects the ecological characteristics of local forest ecosystems and forested landscapes. As such, it is no different from the ecologically-based stage of forestry discussed earlier. The emergence of Ecosystem Management as a new paradigm for U.S. forestry reflects the public pressure to move from the Administrative stage to the Social stage of forestry, and the realization that unless the social forestry paradigm is soundly based in the sciences of forest ecology and landscape ecology, it is unlikely to be successful.

Positions taken by some activist environmentalist groups against forest practices like clearcutting ignore the known ecology of our forests and its variation from region to region. Banning clearcutting and its replacement everywhere by selective or selection harvesting is as environmentally naive as applying clearcutting everywhere. As society seeks a "mid-course correction" in forestry to correct inappropriate practices in the past, it must resist the temptation to "push the tiller hard over". The pendulum in forestry must not be allowed to swing from one mistaken extreme to another mistaken extreme. My interpretation of the Ecosystem Management movement is that it represents an attempt to inject scientific rationality into what had become an irrational debate. Changes in forestry must be guided by our current knowledge of the ecology of the values we seek to sustain over the long-term and not as preconceived biases, whether these be industrial, bureaucratic, economic, social, scientific or "environmental" in origin.

\section{The Paradigm Must be Social Forestry: A Balance Between Ecological, Cultural, Social, Economic and Managerial Considerations, and the Ultimate in "Forest Environmentalism"}

Ecosystem management, while necessary, is not sufficient for the achievement of sustainable, multi-resource forest management. The ecological considerations that embody the ecosystem management paradigm do not adequately consider the role of forests in the cultural fabric of the different societies that make up Canada. They do not address the economic and social costs and benefits associated with an eco-centric approach to forest management. Public participation in planning forestry, aesthetic and spiritual values, and the relative "environmental -friendliness" of wood products in comparison with alternative raw materials are among the list of important additional questions that should be addressed.

Forest environmentalism is concerned with achieving a balance between all these values; a balance that will vary in different parts of Canada and different locations within local forest landscapes. The public's interpretation of "environmentalism" has become confused in many cases with fundamentalist belief systems about nature ("green religion"), and this has distorted the forestry-environmental debate. Environmentalism to me is the balance between social, cultural and ecological considerations.

Defined in this way, environmentalism should become the foundation for the social stage in the evolution of forestry.

\section{Implications of Changing Paradigms for Canada's Timber Supply}

During the exploitation phase, Canada's timber supply was limited only by availability of capital, people, access, transportation and harvesting technology. As we moved into the Administrative phase, regulations on the rate of cut were imposed. Initially, allowable cuts were much lower than today because of technological and market limitations on access, what size of log could be used, and what species and wood quality could be marketed. Over the decades allowable cuts have steadily increased as additional species, smaller logs, and more remote and inaccessible forests could be reached. Allowable cuts reflected mainly the existing operable volume of commercial species (mature and old growth), the rate at which new volume became operable (reflecting rates of tree growth and stand development), and the risks of loss before the volume could be harvested. There were relatively few constraints to reflect non-timber resource values, such as wildlife habitat, aesthetics, stream protection, and to protect soils and slope stability. With tree mortality from fire, insects and disease driving the rate of harvest in many places, the result was rates of harvest that many believe were non-sustainable. The overcutting was exacerbated in some ecological zones by rotations that were too short because experience and regeneration and regrowth rates in more favourable growing environments were uncritically extrapollated to more climatically marginal ecological zones.

With the emergence of an eco-centric paradigm for forstry, all this has changed. More extensive stream protection reserves, more wildlife reserves, more parks, wilderness areas and ecological reserves, green-up restrictions that limit the harvest of adjacent areas until the new forest has re-established environmental control of the harvested areas, and new rules about the landscape pattern of logging are resulting in significant reductions in one or more of area of commercial forest, harvestable volume, and operable volume. Retention of wildlife trees, trees to supply future snags, streamside trees for CWD input into streams, and coarse wood debris contribute to the loss of volume from a site. The rate of timber harvest under these new management objectives will drop significantly.

The desire to sustain log supply in the face of these supply constraints will create pressure to shorten rotations, reduce losses 
to fire, insects and disease (i.e. raise traditional measures of forest health), use commercial thinning and whole-tree harvesting, and apply fertilizers or biological strategies (e.g., nitrogenfixers) to sustain or accelerate growth. However, many of these trends would conflict with the desire for a "more natural" management, with more retention of snags, wildlife trees and coarse wood debris.

Difficult choices will have to be made in defining the acceptable balance between maintaining the ecological conditions implied by the emerging eco-centric paradigm, and maintaining the employment, raw materials, economic wealth and associated social services and values that we have come to depend on from Canada's forests. It is unclear how these choices will be made, and exactly what Canadians will decide should be the paradigm for the future of forest management.

I just hope that in making the decisions, policy makers will base them on a sound understanding of the ecology of the ecosystem values they decide to sustain, and of the social and cultural benefits and costs that will result.

\section{References}

Botkin, D. 1990. Discordant Harmonies: A New Ecology for the Twentyfirst Century. Oxford Univ. Press. $241 \mathrm{pp}$.

Kimmins, J.P. 1993. Ecology, environmentalism and green religion. For. Chronicle 69: 285-289.

Kolb, T.E., M.R. Wagner and W.W. Covington. 1994. Concepts of forest health: utilitarian and ecosystem perspectives. J. Forestry 92(7): 10-15.

Sutton, W.R.J. 1993. For environmental reasons, should we or should we not harvest British Columbia (B.C.) forests? Unpubl. mss. Canadian Forestry Service, Pacific Forest Research Centre, Victoria, B.C.

Woodley, S., J. Kay and G. Francis. 1993. Ecological Integrity and the Management of Ecosystems. St. Lucie Press. Fla. 220 pp. 